areas of life that the problem disappears. Writing on mass society and liberal education, he discerns four major trends of which due account has to be taken in any attempt to secure the wise use of mass media of communication: it might be added that they have equally to be assessed in any rational and imaginative reconstruction of urban communications or conurbations such as Sir Geoffrey Crowther's steering group sought to stimulate in the Buchanan Report. Above all, the book is a convincing plea for the wide and informed discussion of public issues as a precondition of the forma. tion of public policy in which due and sensitive consideration is given to the needs and outlook of the individual.

R. Brightman

\section{GUIDES TO STATISTICAL LITERATURE}

\section{Bibliography of Basic Texts and Monographs on Statisti- cal Methods, 1945-1960}

By William R. Buckland and Ronald A. Fox. Pp. vii +297. (Edinburgh and London: Oliver and Boyd Ltd., 1963. Published for the International Statistical Institute.) $35 s$.

\section{The Annals of Mathematical Statistics}

Indexes to Volumes 1-31, 1930-1960. Compiled under the editorship of J. Arthur Greenwood, Ingram Olkin, and I. Richard Savage. Pp. xiii +658. (St. Paul, Minnesota: North Central Publishing Co., 1962. Published for the Institute of Mathematical Statistics.) $80 s$.

$\mathrm{O}^{\mathrm{F}}$ these two guides to statistical literature, one is conventional while the other provides one of the first published examples of a major new contribution to the art of bibliography-the so-called citation index. Doubtless, its lead will be followed in other fields of learning, and eventually what it achieves will become standard practice in the automated libraries of the future.

Buckland and Fox's Bibliography of Basic Texts and Monographs on Statistical Methods is in the conventional mode. Under ten broad headings, covering both theoretical and applied statistics, it lists the principal books in the literature, their chapter headings, and extracts from published reviews on them. Thus it caters mainly for the student who requires a survey of the subject-matter in book form and who wants some help in choosing between alternative texts. The books mentioned in this bibliography will normally contain references to earlier publications, which in turn will themselves contain further references, and so on: by following such a chain of references, the student who seeks to delve deeper penetrates through the jungle of the literature 'backwards' in time.

Against this, the indexes to the Annals of Mathematical Statistics cater for the research worker who wishes to search 'forwards' through the literature and thereby come on the latest developments in the subject. It contains six different indexes, of which three are citation indexes. The following extract from the primary citation index shows its structure and purpose:

"KaPLANSKY, IRVING

$16: 200-203$. The asymptotic distribution of runs of consecutive elements.

MR 7(1946) 208 W.B.

18 : 574 Kullback

23 : 271 Katz

Canad. J. Math. 8(1956) 234 Mendelsohn

J. Res. Nat. Bur. Standards 64B(1960) 175 Deming

Mitteilungsbl. Math. Statist. 8(1956) 49 Ludwig."

This shows that Kaplansky published a paper entitled "The asymptotic. . ." on pp. 200-203 of Volume 16 of the Annals of Mathematical Statistics. (The above extract does not show the date of publication, but it was in fact 1945 as another part of the index shows.) Later, Kaplansky's paper was reviewed on p. 208 of Volume 7 of Mathematical Reviews in 1946 by a reviewer with initials W.B. Later Kullback, Katz, Mendelsohn, Deming, and Ludwig each wrote a paper citing a reference to Kaplansky's papor. Kullback's paper appeared on p. 574 of Volume 18 of the Annals of Mathematical Statistics in 1947; Mendelsohn's, on p. 234 of Volume 8 of the Canadian Journal of Mathematics in 1956, etc. The links that a citation index automatically affords are those provided by the authors themselves: who better could assess the relevance of ono paper to another?

In this manner, the main citation index lists (alphabetically under authors of the cited paper) all citations (in about 40 selected journals containing material on mathematical statistics) to all papers published in the first 31 volumes of the Annals of Mathematical Statistics. The secondary citation indox does the converse job of listing (alphabetically under tho cited author) all citations in the Annals of Mathematical Statistics to previous papers in about $\mathbf{3 0 0}$ journals (omitting for brevity cited papers which receive only one citation before 1956 and no subsequent citation). The main and secondary citation indexes cover 234 and 78 pages respectively. Tho tertiary citation index (covoring 26 pages) lists (alphabetically under about 300 journals) all authors who have been cited in the Annals of Mathematical Statistics, and thereby provides an alternative method of entering the secondary citation index. The tertiary citation indox also allows editors of (and prospective authors in) the 300 journals to appraise how much notice is taken of papers on mathematical statistics published therein.

The three other indexes in the volume - a subject index, an index of tables, and an index of news items-are of conventional type, though of more than ordinary thoroughness. The subject index, covering 302 pages, gives (for the first 31 volumes of the Annals) one or more entries for the general theme of each published paper as well as entries for the specific contents of individual pages in each paper. The index of tables (10 pages) lists by subjectmatter all numerical tables of mathematical functions in the first 31 volumes.

This volume must be one of the most comprehensive works of indexing ever undertaken in scientific work, and, in particular, the citation indexes are new and most valuable developments. The only possible regret is that similar citation indexes are not yet available for other journals, for their absence limits a search forwards through the literature when that literature passes outside the immediate field of the Annals of Mathematical Statistics. Of course, the labour involved in compiling a citation index is tremendous, and in the present case was only made possible by grants from the National Science Foundation. To pursue similar independent projects for individual areas of science would lead to a wasteful overlapping of effort. What is suroly needed-and needed all the more as the literature grows and interpenetrates-is a single central indexing facility considered as part and parcel of the functions of a library. How long will it bo-for that time must surely come some day-before one is ablo to communicate direct from one's own desk with the central computing store of a national (or even an international) library, into which all incoming material is indexed on arrival and provided with the appropriate coding and addressing to keep the rolevant citation indexes up to date? The University of Chicago has recently appointed a physicist to bo dean of its Library Sciences Division. Librarianship in the future will become a task less for the bibliophile and more for the electronic engineer. With the publication of these indexes for the Annals of Mathematical Statistics, the writing is alroady on the library wall.
J. M. HAMMERSIEY 